\title{
O ENSINO MÉDIO BRASILEIRO E A LEI No 13.415/2017 EM TEMPOS DE NEOLIBERALISMO: FORMAÇÃO PARA EMANCIPAÇÃO OU FORMAÇÃO PARA O MERCADO?
}

\section{BRAZILIAN HIGH SCHOOL AND LAW NO 13.415/2017 IN NEOLIBERALISM: TRAINING FOR EMANCIPATION OR TRAINING FOR THE MARKET?}

\author{
SANTOS, Dayanna Pereira ${ }^{1}$ \\ CARVALHO, Edson Silva² \\ OLIVEIRA, Eudiane Nunes de ${ }^{3}$
}

\begin{abstract}
RESUMO
O artigo objetiva analisar as principais ações da política educacional para o Ensino Médio no contexto da Lei no 13.415 , sob a influência do neoliberalismo. Para se problematizar o objeto de estudo e abordar as questões de investigação, trabalhou-se com teóricos como Cunha (2005); Kuenzer (1997); Freitas (2018), Motta; Frigotto (2017). Sob esse prisma, os documentos oficiais conexos a essas políticas foram mapeados e analisados, problematizando-se os interesses políticos e econômicos em voga; as disputas ideológicas contemporâneas, conferindo atenção à flexibilização curricular e à concepção de competências no âmbito do ensino. Os resultados permitiram identificar contradições nos discursos oficiais e na implantação e concretização das políticas de Ensino Médio, desvelando um distanciamento entre o pretendido e o realizado. Ademais, identificou-se que a proposta de criação dos IFs configura-se como possibilidade de superação do modelo formativo economicista, na medida em que desenvolve um processo formativo de unidade entre o trabalho, a ciência e a cultura.
\end{abstract}

PalaVRas-Chave: Ensino Médio, Reforma, Formação, Política Educacional.

\section{ABSTRACT}

The article aims to analyze the main actions of the educational policy for High School in the context of Law No. 13,415, under the influence of neoliberalism. To problematize the object

\footnotetext{
${ }^{1}$ Pós- Doutoranda pela Universidade Federal de Minas Gerais. Doutora e Mestre em Educação pela Universidade Federal de Goiás. Docente no Mestrado Profissional de Educação Profissional e Tecnológica - IFG. Goiás, GO, Brasil. e-mail: dayannagyn@hotmail.com

2 Mestrando em Educação Profissional e Tecnológica - IFG. Goiás, GO, Brasil. e-mail: edson.carvalho@ifg.edu.br

3 Mestranda em Educação pela Universidade Federal de Goiás. Goiás, GO, Brasil. e-mail: dayanna.santos@ifg.edu.br
} 
DOI: $10.12957 / \mathrm{e}-\mathrm{mosaicos} .2019 .46491$

of study and address the research questions, we worked with theorists such as Cunha (2005); Kuenzer (1997); Freitas (2018), Motta; Frigotto (2017). In this light, the official documents related to these policies were mapped and analyzed, problematizing the current political and economic interests; contemporary ideological disputes, paying attention to the curricular flexibility and the conception of competences in the scope of teaching. The results allowed us to identify contradictions in the official speeches and in the implementation and implementation of high school policies, revealing a gap between the intended and the realized. Moreover, it was identified that the proposal for the creation of FIs is configured as a possibility of overcoming the economicist formative model, as it develops a formative process of unity between work, science and culture.

KeYwORDS: High School, Retirement, Training, Educational Policy.

\section{As POLÍTICAS PARA O ENSINO MÉDIO NO PERÍODO DE 1930 A 1990: ESTRATÉGIAS E CONCEPÇÕES}

Ao traçar um histórico da educação profissional no Brasil, Cunha (2005) expõe que a "Revolução de 1930" foi um referencial do desenvolvimento capitalista no Brasil e sinaliza um período de realinhamento dos interesses dominantes com a substituição do modelo capitalista dependente agrário-exportador pelo modelo, também capitalista e dependente, urbano-industrial, que se tornou hegemônico a partir de 1945. Nesse contexto, as iniciativas do Estado foram voltadas para a organização das estruturas de um "Estado-nação" e de um "Estado-capitalista" no país, por meio de intervenções que primavam pela conciliação como categoria de sua existência e progresso.

Era notável, portanto, a demanda pelo processo de industrialização e isso exigia profissionais especializados para a indústria, comércio e prestação de serviços. As bases para a modernização econômica, política e administrativa do país surgiram logo no início do governo de Getúlio Vargas (1930-1934), o chamado "Governo Provisório". Sobre isso, Moura (2007) afirma que o processo de industrialização e modernização das relações de produção da sociedade brasileira exigiu uma postura mais participante dos dirigentes frente à educação nacional e como reação foram promulgados diversos decretos-leis para regulamentar a estruturação da educação.

É nesse contexto que, já no final de 1930 com a criação do Ministério da Educação e Saúde Pública, sinalizava-se a tonificação do Estado educador, sendo então indicado Francisco Campos como o seu primeiro titular. Após sua nomeação, na primeira metade de 1931, ele coloca em vigor uma significativa reforma na educação nacional com destaque para a criação do Conselho Nacional de Educação e a reorganização do ensino secundário e superior, que passaria a ser identificada com o seu nome - Francisco Campos. Essa reforma foi oficializada pelo Decreto n. ${ }^{0}$ 18.890, de 18 de abril de 1931, sendo ajustada e consolidada pelo Decreto n. ${ }^{0}$ 
DOI: $10.12957 / \mathrm{e}-\mathrm{mosaicos} .2019 .46491$

21.214, de 4 de abril de 1932 (SAVIANI, 2007).

Ademais, Saviani (2007) afirma que, por um lado, a referida Reforma produziu organicidade ao ensino secundário por meio de várias estratégias escolares, como a seriação do currículo, a frequência obrigatória dos alunos, a imposição de um detalhado e regular sistema de avaliação discente e a reestruturação do sistema de inspeção federal. Nesses termos, a cultura escolar deliberada pela Reforma de 1931 objetivava produzir um habitus burguês nos jovens secundaristas, a partir da educação integral e de práticas de disciplinamento e de autogoverno.

No entanto, por outro lado, a priori, destacamos que a Reforma Francisco Campos, de caráter prescritivo e normativo, pautou-se pela dualidade educacional na medida em que não permitia aos estudantes da educação profissional o prosseguimento aos estudos superiores. Sob esse prisma, inibia-se a participação das classes mais baixas no ensino secundário e, por conseguinte, a educação profissional não recebia o investimento e zelo necessário, limitando-se ao ensino comercial que não dava acesso ao ensino superior.

Desse modo, tais preceitos legais prejudicavam a livre ascensão social das classes mais pobres, conservando a educação propedêutica e a profissional direcionadas para rumos distintos, uma vez que a elite tinha acesso ao ensino propedêutico, enquanto os pobres ficavam restritos à educação puramente técnica e voltada para um fim em si mesmo. Interessa pontuar que a dicotomia social presente na história do Brasil balizou também a formação do sistema educacional brasileiro ao afiançar, através de instrumentos legais, a manutenção de direitos àqueles pertencentes às classes sociais detentoras dos meios de produção.

Nesse contexto, com o aumento do número de anos do ensino secundário, destinado à formação das elites, e a sua divisão em dois ciclos, foi conferida ao ensino secundário uma composição mais complexa, que incluía dispositivos mais específicos aos cursos superiores. Essa nova configuração alinhava o Brasil aos países ocidentais mais desenvolvidos, que, pelo menos, desde fins do século XIX, modernizaram o ensino secundário também através da criação de dois ciclos. A divisão criada pela Reforma Francisco Campos (1931) foi ressignificada na Lei Orgânica do Ensino Secundário de 1942.

Assim, Capanema, auxiliado por Lourenço Filho, estabelece normas e mecanismos que permitissem ao Ministério da Educação atuar sobre a educação nacional. Logo, define ciclo ginasial de quatro anos, e o ciclo colegial de três anos, divisão conservada na estrutura do ensino brasileiro até o início da década de 1970, quando foi instituído o $1^{\circ}$ grau, a partir da fusão do curso primário com o ciclo ginasial, e o $2^{\circ}$ grau formado pelo ciclo colegial.

A Reforma Capanema (1942-1946), operada durante o governo Vargas, autoritário e de postura subserviente perante o capital industrial nacional e internacional, reconfigurou a estrutura moderna do ensino secundário brasileiro estabelecida pela Reforma Francisco Campos. Nessa época, o discurso oficial 
DOI: $10.12957 / \mathrm{e}-m o s a i c o s .2019 .46491$

asseverava a necessidade de novas frentes de formação de mão de obra qualificada para a indústria nacional. A assimilação desse ideário fez com se fixasse, no discurso em voga, uma relação direta entre formação e emprego, nem sempre real.

Assim, no curso da reforma dirigida pelo ministro da Educação Gustavo Capanema, houve a valorização de conteúdos nacionalistas - acondicionada pelo clima do Estado $\mathrm{Novo}^{4}$-, mas o ensino secundário não modificou substancialmente as suas finalidades e a sua estrutura. $O$ ensino técnico-profissional, voltado à formação de trabalhadores, foi implementado por três Decretos-Leis: ensino industrial (Decreto-Lei n. ${ }^{\circ} 4.073$, de 30 de janeiro de 1942); ensino comercial (Decreto-Lei n. ${ }^{\circ} 6.141$, de 28 de dezembro de 1943); ensino agrícola (Decreto-Lei n. ${ }^{\circ} 9.613$, de 20 de agosto de 1946). Vale lembrar que, em 1942, houve ainda a criação do Senai, em seguida do Senac, em 1946, e dos demais " $S$ "5 ao longo das décadas seguintes, revelando, dessa forma, a opção governamental de privatizar a tarefa de preparar "mão de obra" para o setor industrial.

Cabe destacar que o Decreto n. ${ }^{0}$ 4.127, de 25 de fevereiro de 1942, transforma as Escolas de Aprendizes e Artífices em Escolas Industriais e Técnicas, passando a promover a formação profissional em nível análogo ao do secundário. A partir desse ano, inicia-se, convencionalmente, o processo de articulação do ensino industrial à estrutura do ensino do país como um todo, uma vez que os alunos formados nos cursos técnicos ficavam autorizados a ingressar no ensino superior em área equivalente à da sua formação.

Todavia, Kuenzer (1997) esclarece que a dualidade educacional e social continua sendo reafirmada, já que o acesso ao ensino superior, via processo seletivo, continuava ocorrendo em função do domínio dos conteúdos gerais, das letras, das ciências e das humanidades, assumidos como únicos conhecimentos válidos para a formação da classe abastada. É possível considerar que a Reforma Capanema foi um desdobramento da Reforma Francisco Campos no que diz respeito ao surgimento de novas instituições, tais como escolas técnicas e industriais, à centralização da gestão no âmbito federal e também à intensificação do caráter pragmático do ensino centrado na teoria do capital humano.

A esse respeito, Saviani (2007, p. 269) diz que:

Do ponto de vista da concepção, o conjunto das reformas tinha

\footnotetext{
${ }^{4}$ O Estado Novo compreendeu o período em que o Brasil foi governado por Getúlio Vargas, entre os anos de 1937 a 1945, o qual foi marcado pelo autoritarismo, censura e centralização do poder.

${ }^{5}$ Sistema S é o nome pelo qual ficou convencionado de se chamar o conjunto de nove instituições voltadas para o treinamento profissional, assistência social, consultoria, pesquisa e assistência técnica, sendo elas : Serviço Nacional de Aprendizagem Industrial (Senai); Serviço Social do Comércio (Sesc); Serviço Social da Indústria (Sesi); Serviço Nacional de Aprendizagem do Comércio (Senac); Serviço Brasileiro de Apoio às Micro e Pequenas Empresas (Sebrae); Serviço Nacional de Aprendizagem Rural (Senar); Serviço Nacional de Aprendizagem do Cooperativismo (Sescoop); Serviço Nacional de Aprendizagem do Transporte (Senat) e Serviço Social de Transporte (Sest).
} 
caráter centralista, fortemente burocratizado, dualista, separando o ensino secundário, destinado às elites condutoras, do ensino profissional, destinado ao povo conduzido e concedendo apenas ao ramo secundário a prerrogativa de acesso a qualquer carreira de nível superior; corporativista, pois vinculava estreitamente cada ramo ao tipo de ensino as profissões e ofícios requeridos pela organização social.

Com efeito, observamos que os decretos-leis que iniciaram com Capanema se desdobraram até a aprovação da primeira Lei de Diretrizes e Bases da Educação Nacional, em 1961, que reforçou a dualidade característica da educação brasileira. Nessa lógica, o governo de Juscelino Kubitschek (1956-1961) aprofunda a relação entre Estado e economia, na medida em que toma a indústria automobilística como ícone da consolidação da indústria nacional.

Nesse contexto de busca pela modernização do país, após ampla discussão teórica sobre as transformações necessárias para que a educação brasileira também se modernizasse, ocorre a aprovação da primeira Lei de Diretrizes e Bases da Educação Nacional - LDB 4.024/61, sancionada pelo então presidente João Goulart. Na concepção de Saviani (2007), a Lei foi apreciada como a unificação entre a rede de escolas públicas e as escolas privadas, sob a mesma inspiração direta e indireta de uma concepção produtivista da escola. Por meio dela era gerida a concessão de bolsas, o investimento de recursos no desenvolvimento do sistema público, bem como a iniciativa privada através de subvenções financeiras. Também se pressupunha a cooperação entre União, Estados e Municípios.

No que tange à educação profissional, a lei analisada defendia a liberdade de métodos, a flexibilidade curricular e a diversificação de ferramentas avaliativas. Nessa LDB, houve, pois, uma primeira tentativa de articulação entre o ensino propedêutico e o ensino técnico ao permitir que o aluno egresso do ensino profissionalizante também pudesse ingressar no ensino superior. Contudo, os vestígios da dualidade educacional são realçados pelo fato de que o estudante que saísse do ensino profissionalizante deveria optar entre os cursos vinculados à sua área específica de formação técnica. Ou seja, não the era permitido escolher livremente o curso desejado, pois havia um direcionamento dado a priori pela base técnica.

Prevalece, portanto, a ênfase no aspecto quantitativo, nos meios e técnicas educacionais, na formação profissional e na adaptação do ensino às demandas da produção industrial. Essas adaptações foram transversalmente influenciadas por essa reestruturação do sistema capitalista marcada por "políticas de centralização, de diferenciação e de diversificação institucional e, especialmente, de privatização da esfera pública" (DOURADO, 2002, p. 235). Isso implica considerar a educação também como espaço de disputas, caracterizado por conflitos que envolvem as contradições inerentes às relações entre o público e o privado. 
DOI: $10.12957 /$ e-mosaicos.2019.46491

Sob tal lógica, no decorrer do período da ditadura militar, de 1964 a 1985, os investimentos empreendidos em obras e complexos industriais demandavam do Estado a ampliação de programas de formação de mão de obra. Assim, dando continuidade à proposta do governo militar, com ênfase na formação de mão de obra, foi instituída a nova lei (LDB 5692/71), que mudou a organização do ensino no Brasil e designou a "profissionalização universal e compulsória para o ensino secundário" e alterou as nomenclaturas primário e secundário para $1^{\circ}$ e $2^{\circ}$ graus, respectivamente. Nesse caso, o $2^{\circ}$ grau passou a ter como principal objetivo a profissionalização. Em curto e médio prazo, as escolas públicas desse nível deveriam tornar-se profissionalizantes.

Kuenzer (1997) destaca que essa proposta fracassou mediante a escassez de recursos e estrutura física e pedagógica das escolas, especialmente as estaduais, que ofereciam cursos em que se exigia baixa qualificação, suscitando um contingente significativo de desempregados e de estudantes sem qualificação técnica para se inserir no mercado de trabalho. Concomitantemente, faltava também ao ensino propedêutico o investimento necessário para aprovação dos jovens em processos seletivos para o ingresso no ensino superior.

Seguindo esses pressupostos, em 1978, houve a transformação de três Escolas Técnicas Federais - Paraná, Minas Gerais e Rio de Janeiro - em Centros Federais de Educação Tecnológica - CEFET, através da Lei $n .{ }^{\circ}$ 6.545, que outorga a essas instituições autorização para formar engenheiros de operação e tecnólogos, fundamentando-se no Decreto n. ${ }^{\circ}$ 547, de 18 de abril de 1969. Dessa forma, em virtude da mencionada lei, essas instituições passaram a se distinguir das demais Escolas Técnicas, tendo sua atuação expandida através da permissão de organizar e ofertar cursos superiores e também cursos de pós-graduação lato sensu e stricto sensu, ambicionando a formação de profissionais e especialistas na área tecnológica.

Nesse contexto, por mais de uma década, apenas três CEFET existiram no país $^{6}$, porém, por meio da Lei n. ${ }^{\circ} 8.948$, de 8 de dezembro de 1994 , foi instituído o Sistema Nacional de Educação Tecnológica, transformando as antigas escolas técnicas em Cefets. Consequentemente, após a mencionada lei, as demais escolas técnicas e agrotécnicas federais foram se transformando, paulatinamente, em Centros Federais de Educação Tecnológica, isso mediante os parâmetros determinados pelo Ministério da Educação, levando em consideração a infraestrutura, desde equipamentos a servidores, como condições mínimas necessárias para que as novas atividades fossem realizadas, que deveriam ser comprovados pela instituição em projetos próprios elaborados exclusivamente para o pleito de sua transformação em CEFET.

Na sequência, em 20 de dezembro de 1996, a Lei n.o 9.394 é sancionada.

\footnotetext{
${ }^{6}$ É preciso considerar a criação dos CEFETs do Maranhão e da Bahia, por leis específicas, antes da Lei no 8948/1994. Portanto, existiram 5 CEFETs antes desta lei.
} 
DOI: $10.12957 / \mathrm{e}-m o s a i c o s .2019 .46491$

Nessa nova lei, a educação básica e profissional é tratada em capítulos diferentes. Sendo assim, o capítulo primeiro é destinado à educação básica, que passou a ser composta por educação infantil, ensino fundamental e ensino médio. No artigo 35 , o Ensino Médio é apresentado como etapa conclusiva da educação básica, com duração de no mínimo três anos. O ensino médio tem como objetivo promover sequência à aprendizagem atingida no ensino fundamental, possibilitando condições para que esses estudos pudessem ter continuidade, proporcionando habilitação mínima para o trabalho e cidadania, formação humana, ética, autônoma, intelectual e crítica (BRASIL, 1996).

Já no segundo capítulo, a Lei n. ${ }^{0} 9.394$, no artigo 39, estabelece que "a educação profissional, integrada às diferentes formas de educação, ao trabalho, à ciência e à tecnologia, conduz ao permanente desenvolvimento de aptidões para a vida produtiva (BRASIL, 1996)". É afirmado que a educação profissional "será desenvolvida em articulação com o ensino regular ou por diferentes estratégias de educação continuada, em instituições especializadas ou no ambiente de trabalho (BRASIL, 1996)". Sob esse prisma, a lei determina que o conhecimento adquirido fora do ensino regular pode ter reconhecimento e certificação, desde que passado por uma avaliação, possibilitando habilitação para outras etapas de estudo ou mesmo conclusão.

Nesse contexto, a formação para o trabalho e a capacitação profissional são compreendidas de forma dual. A esse respeito, Moura (2007, p. 13) afirma

Como a educação brasileira é estruturada na nova LDB em dois níveis - educação básica e educação superior, e a educação profissional não está em nenhum dos dois, consolida-se a dualidade de forma bastante explícita. Dito de outra maneira, a educação profissional não faz parte da estrutura da educação regular brasileira. É considerada como algo que vem em paralelo ou como um apêndice e, na falta de uma denominação mais adequada, resolveu-se tratá-la como modalidade, o que efetivamente não é correto.

Conforme exposto no fragmento acima, é possível percebermos uma dicotomia existente entre as modalidades de ensino, entre a elite e a classe menos privilegiada. Conforme Saviani (2007), o papel fundamental da escola de nível médio seria então o de recuperar a relação entre o conhecimento e a prática do trabalho, envolvendo o domínio não apenas teórico, mas também prático sobre o modo como o saber se articula com o processo produtivo.

É sob essa perspectiva que no governo de Fernando Henrique Cardoso (FHC), num ato autoritário e antidemocrático, instituiu-se o Decreto n. ${ }^{\circ} 2.208 / 1997$, cujo objetivo foi o de separar o ensino médio da educação profissional. Com o referido decreto, o ensino médio passa a ser totalmente propedêutico, enquanto o ensino 
DOI: $10.12957 / \mathrm{e}-m o s a i c o s .2019 .46491$

técnico passa a ser ofertado de forma concomitante com matrícula e currículos separados, podendo ser cursado na mesma instituição (concomitância interna), ou em diferentes instituições (concomitância externa). Os cursos subsequentes eram oferecidos para aqueles que haviam concluído o ensino médio.

No contexto do Decreto n. ${ }^{\circ}$ 2.208/1997 também foi criado o Programa de Expansão da Educação Profissional - PROEP, que almejava a implementação de um novo modelo de educação profissional. Para tanto, com recursos oriundos do Banco Interamericano de Desenvolvimento (BID), expandiu-se a oferta do número de vagas e criaram-se novos cursos, voltados, sobretudo, para as necessidades do mercado. Moura (2007, p. 14) analisa o PROEP da seguinte forma

\begin{abstract}
Apesar da crítica radical que merece essa fúria privatizante que transferiu grande parte do patrimônio público nacional à iniciativa privada a baixos custos, é necessário reconhecer que a reforma da EP e o PROEP foram extremamente coerentes com a lógica neoliberal que os patrocinou, de forma que ao serem analisados a partir dessa perspectiva, aparecem como muito "eficientes".
\end{abstract}

O PROEP foi um programa de investimento financeiro que teve por objetivo colocar em prática os novos dispositivos legais da reforma da educação profissional Lei de Diretrizes e Bases 9.394/1996, Decreto n. ${ }^{\circ}$ 2.208/1997 e Portaria do MEC n. ${ }^{\circ}$ $646 / 1997$ - por meio do financiamento na infraestrutura das escolas, na gestão da educação profissional e no desenvolvimento técnico-pedagógico das instituições. No caso do PROEP, verificamos a existência de uma descentralização de tipo administrativo e não de tipo político, porque a função assumida pela União foi a de centralizar o desenho, a definição e a implementação da política. Nessa perspectiva, operam-se a redução da mediação estatal e o fortalecimento de responsabilidades da sociedade civil.

Segundo Moura (2007), a expansão do setor privado em um contexto de diminuição de fiscalização e controle de recursos provoca o aumento da diferenciação interna da oferta educativa. Segundo esta hipótese, o ensino privado estaria assumindo características cada vez mais massivas, sem compromisso com a formação de caráter humano e crítico. Com efeito, as propostas contidas no PROEP em relação ao ensino profissionalizante apoiaram-se numa perspectiva neoliberal de ensino, a qual enfatiza a necessidade de formar cidadãos aptos para atuarem no mercado de trabalho e não para serem críticos e emancipados intelectualmente.

\title{
O ENSINO MÉDIO INTEGRADO À EDUCAÇÃO PROFISSIONALIZANTE: AVANÇOS E LIMITES
}

Segundo Kuenzer (2006), o Decreto n. ${ }^{0} 2.208 / 97$ é revogado pelo Decreto n. ${ }^{\circ}$ 
DOI: $10.12957 /$ e-mosaicos.2019.46491

5.154/04, instituído no governo do presidente Luís Inácio Lula da Silva (Lula). Com o Decreto n. ${ }^{0} 5.154$ foi restabelecido o ensino médio integrado como forma de oferta da educação profissional articulada ao ensino médio. Nesse contexto, o Conselho Nacional de Educação ratifica as diretrizes curriculares para o ensino médio e para a educação profissional anteriores ao Decreto $n \cdot{ }^{\circ}$ 5.154/2004, propondo, em relação ao ensino médio integrado, somente ajustes de carga horária. As formas de oferta concomitante e subsequente foram mantidas, referendando-se, assim, a independência entre formação média e profissional, que podem ser ministradas como partes autônomas, embora integrantes do mesmo curso.

Na concepção da autora, o Decreto no 5.154/2004 expandiu o conjunto de alternativas com o ensino médio integrado sem, contudo, inibir ações privadas de formação precarizada com recursos públicos. O novo decreto não reafirma, em sua totalidade, a primazia da oferta pública, pois também viabiliza, por meio de políticas públicas, a possibilidade de as instituições privadas continuarem se beneficiando financeiramente por meio da "venda" de cursos como aconteceu no Senai, Senac e Sebrae.

Em 2008, ocorre outra reformulação no ensino profissionalizante, isso através da Lei n. ${ }^{0}$ 11.892/2008, que reorganiza a Rede Federal de Educação Profissional e Tecnológica com a criação dos Institutos Federais de Educação Tecnológica (IFET). Os IFET são constituídos como instituições de educação superior, básica e profissional, pluricurriculares e multicampi, especializadas na educação profissional e tecnológica nas diferentes modalidades de ensino, desde a educação de jovens e adultos profissionais até doutorado profissional. Cerca de metade do orçamento dos IFET seria destinada à oferta de cursos profissionalizantes de nível médio. A proposta teve como finalidade fortalecer o ensino técnico integrado ao médio, a educação de jovens e adultos e a formação inicial e continuada de trabalhadores da educação.

Sob esse prisma, busca-se atuar de forma integrada, alicerçando suas ações no tripé trabalho, cultura e ciência como forma de assegurar a emancipação humana. Nessa perspectiva, a formação profissional é concebida como espaço para o aprofundamento de saberes e, simultaneamente, para a refutação de tônicas sociais excludentes. Nas palavras de Ramos (2007, p. 3), "uma educação dessa natureza precisa ser politécnica, isto é, uma educação que, ao propiciar aos sujeitos o acesso aos conhecimentos e à cultura construídos pela humanidade, propicie a realização de escolhas e a construção de caminhos para a produção da vida".

Nesse sentido, o ensino médio integrado tem como objetivo promover, de um lado, a superação da dualidade escolar entre formação geral e profissional, de outro, o incentivo à formação "integral", embasada numa noção de "politecnia", respaldada na formação do homem omnilateral ${ }^{7}$. A noção de politecnia ou instrução politécnica é parte da formação integral. No que tange à educação do corpo, esta deveria

\footnotetext{
${ }^{7}$ Segundo Frigotto (2012, p. 267), o termo omnilateral "vem do latim e sua tradução literal significa "todos os lados ou dimensões".
} 
DOI: $10.12957 / \mathrm{e}-\mathrm{mosaicos} .2019 .46491$

equilibrar os efeitos nocivos do trabalho à saúde, sobretudo no sistema industrial. Em relação à dimensão intelectual, considera-se a necessidade de abranger a totalidade das ciências, pois, com o domínio dos conhecimentos científicos e tecnológicos que explicam e fundamentam o trabalho produtivo, a classe operária poderia romper as desigualdades sociais. Nesse caso, a formação omnilateral faz-se em oposição à formação unilateral causada pelo trabalho alienado, pela divisão social do trabalho, pela reificação, pelas relações burguesas.

Para Ramos (2007, p. 3-4), o primeiro sentido dessa integração é filosófico, visto que se manifesta na

concepção de formação humana, com base na integração de todas as dimensões da vida no processo formativo. O primeiro sentido da integração ainda não considera a forma ou se a formação é geral ou profissionalizante. O primeiro sentido da integração pode orientar tanto a educação básica quanto a educação superior. A integração, no primeiro sentido, possibilita formação omnilateral dos sujeitos, pois implica a integração das dimensões fundamentais da vida que estruturam a prática social. Essas dimensões são o trabalho, a ciência e a cultura.

Nesse caso, o trabalho é tomado em seu sentido ontológico, ou seja, intrínseco à vida humana, e não meramente a comercialização de força produtiva para ganho financeiro. Portanto, trabalho é produção, criação, realização humanas. Compreender 0 trabalho nessa perspectiva "é compreender a história da humanidade, as suas lutas e conquistas mediadas pelo conhecimento humano" (RAMOS, 2007, p. 4). Ora, trabalho e ciência se interligam, já que ação humana é promotora de conhecimentos.

Nesse contexto, destacam-se, para a constituição integrada de processos formativos, a cultura, os valores e as normas que identificam um determinado grupo social, uma vez que esses "compartilham valores éticos, morais, simbólicos que organizam a sua ação e a produção estética, artística" (RAMOS, 2007, p. 4). Portanto, assimilar o vínculo intrínseco entre trabalho, ciência e cultura consiste em interpretá-lo como princípio educativo, que se opõe à ideia do "aprender fazendo" e da formação exclusiva para a profissão.

Ciavatta (2008), inspirada na teoria gramsciana, afirma que priorizar o trabalho como princípio educativo significa que almejamos "superar a dicotomia trabalho manual/trabalho intelectual, de incorporar a dimensão intelectual ao trabalho produtivo, de formar trabalhadores capazes de atuar como dirigentes e cidadãos" (GRAMSCI, 1981 apud CIAVATTA, 2008, p. 6). Isso significa compreender o trabalho como princípio educativo, representa considerar que o ser humano produz e transforma sua própria realidade, sendo sujeito de sua própria existência. 
DOI: $10.12957 /$ e-mosaicos.2019.46491

Em síntese, o trabalho assume a dimensão ontológica, compreendendo o princípio educativo, como também se estabelece como prática econômica, de subsistência, produzindo bens materiais para atender às necessidades humanas, englobando a realidade social e material. No entanto, a formação, em especial a profissionalizante, não deve se basear unicamente na dimensão econômica, tornando-se preparo para o mercado de trabalho, mas sim qualificar o ser humano para a emancipação, possibilitando a "compreensão das dinâmicas socioprodutivas das sociedades modernas, com as suas conquistas e os seus revezes, e também habilitar as pessoas para o exercício autônomo e crítico de profissões, sem nunca se esgotar a elas" (RAMOS, 2007, p. 5).

Compreendemos, dessa forma, que a educação profissional deve subsidiar meios para que o sujeito possua condições de compreender a práxis econômica da sociedade, ao mesmo tempo que the dê condições de atuar ativamente nela. Isso equivale dizer que essa educação deve seguir os moldes de uma formação politécnica, em que se compreenderia a formação intelectual, física e tecnológica. Logo, o ensino politécnico, de preparação integral, seria o único capaz de dar conta do movimento dialético de continuidade-ruptura presente no sistema econômico da sociedade. $\mathrm{O}$ ensino politécnico, ao mesmo tempo em que atua sobre os sujeitos, contribui para o desenvolvimento de condições objetivas de transformação da sociedade.

Portanto, para que essa formação se realize, deve fundamentar-se nos preceitos da formação omnilateral que indica que o trabalho está intimamente vinculado ao desenvolvimento humano na perspectiva da formação do homem para a emancipação, baseando-se no desenvolvimento integral, em todos os sentidos, das faculdades e das forças produtivas. Assim, a única forma possível de o homem tornar-se integral seria por meio da formação omnilateral. Sendo assim, a formação dos indivíduos carece de articulação entre teoria e prática, entre manual e intelectual, num elo interdependente.

Todavia, na atualidade, a Educação Profissional e Tecnológica (EPT) de nível médio no Brasil registra um cenário político de reordenamento estrutural por meio da Lei n. ${ }^{0}$ 13.415, sancionada em 16 de fevereiro de 2017, que estabelece a Reforma do Ensino Médio e, por conseguinte, a homologação da Base Nacional Curricular Comum (BNCC). Segundo Frigotto (2017), a Reforma constitui-se por meio de um conjunto de novas diretrizes para o ensino médio implementado com o objetivo de flexibilizar o conteúdo que será ensinado aos alunos, alterando, portanto, a distribuição dos conteúdos disciplinares no curso dos três anos do ciclo. Nesse contexto, o ensino técnico ganha destaque como instrumento formativo de preparação para o mercado de trabalho.

Na contramão dessa proposição, tem-se a educação ofertada pela Rede Federal de Educação Profissional, Científica e Tecnológica, que prevê a formação e qualificação de cidadãos para "atuação profissional nos diversos setores da economia, com ênfase no desenvolvimento socioeconômico local, regional e 
DOI: $10.12957 / \mathrm{e}-\mathrm{mosaicos} .2019 .46491$

nacional" (BRASIL, 2008). Essa Rede tem como compromisso a formação de sujeitos críticos, humanizados e emancipados, através de uma educação que proporcione experiências com o intuito de despertar o

senso crítico, elevando o sujeito a patamares de compreensão capazes de ampliar seu nível de participação na esfera social, sem negligenciar a relação do homem com as questões de socialização, com as tecnologias, com os desafios ambientais e com a totalidade do complexo mundo do trabalho (FDE/CONIF, 2016, p. 12).

À luz dessa proposição, foi elaborada, em novembro de 2017, uma minuta de Parâmetros Gerais, que busca de promover elementos que fundamentem a resistência em prol dos Cursos Integrados na Rede de EPCT. Essa minuta foi criada durante reunião do Fórum de Dirigentes de Ensino-FDE, formado pelo Grupo de Trabalho dos Cursos Integrados, no qual foi proposta ao Conselho Nacional das Instituições da Rede Federal de Educação Profissional, Científica e TecnológicaCONIF a organização de diretrizes ou parâmetros gerais para a oferta de cursos integrados como política prioritária de educação profissional na Rede Federal de Educação Profissional, Científica e Tecnológica-Rede Federal de EPCT. Para isso, também foram elaborados dois documentos, um em 2016, o Documento Base para a promoção da formação integral, fortalecimento do ensino médio integrado e implementação do currículo integrado no âmbito das Instituições da Rede EPCT, conforme Lei n. ${ }^{0}$ 11.892/2008; e outro em 2017, a Agenda de Fortalecimento do Ensino Médio Integrado na Rede Federal.

Na minuta, são abordadas considerações acerca dos

Dados dos cursos integrados na Plataforma Nilo Peçanha - PNP; Fundamentos e base legal dos Cursos Integrados; Reflexão sobre os cursos integrados no FDE - documentos de 2016 e 2017; Parâmetros gerais para os Cursos Integrados na Rede Federal de EPCT (FDE/CONIF, 2016, p. 2).

Nesse documento, foi evidenciada a necessidade de criação de vagas para cursos técnicos, priorizando os cursos integrados e almejando, dessa forma, o cumprimento do que está determinado no art. $8^{\circ}$ da Lei n. ${ }^{0}$ 11.892/2008: "No desenvolvimento da sua ação acadêmica, o Instituto Federal, em cada exercício, deverá garantir o mínimo de $50 \%$ (cinquenta por cento) de suas vagas para atender aos objetivos definidos no inciso I do caput do art. 70 (BRASIL, 2008)". De acordo 
DOI: $10.12957 / \mathrm{e}-\mathrm{mosaicos} .2019 .46491$

com a Plataforma Nilo Peçanha - $\mathrm{PNL}^{8}$, para se garantir essa determinação legal, será preciso ampliar em torno de $8 \%$ do total de suas vagas, o que seria aproximadamente 40 mil vagas a mais para a oferta de Cursos Integrados.

Outro dado importante que a PNL apresenta refere-se ao público atendido pelos Cursos Integrados da Rede Federal de EPCT, validando, por meio dos resultados de pesquisa socioeconômica, que a rede está alcançando o público que mais carece de formação integrada

quadro socioeconômico do país ainda evidencia a necessidade da educação como estratégia de desenvolvimento e inclusão social para a garantia do acesso, permanência e êxito de estudantes em sua trajetória acadêmica. [...]. Quando o quesito é Renda Familiar, embora $45 \%$ não tenha declarado renda, a maioria dos que declararam situam-se na faixa de renda de até 1,5 Salários Mínimos per capita, [...]. Excluindo-se o percentual de Não Definidos - N/D, que do ponto de vista estatístico deveriam ser distribuídos proporcionalmente nos estratos, $74 \%$ dos estudantes são oriundos de famílias de até 1,5 SM per capita (FDE/CONIF, 2016, p. 7).

Ao que tange os fundamentos e base legal dos Cursos Integrados, a minuta evidencia a Lei no 11.892/2008, que dispõe sobre a criação dos IF, reiterando que a oferta de Cursos Integrados é uma determinação legal para a Rede Federal de EPCT, não cabendo, portanto, a alternativa de não oferta. Cita também o Parecer CNE/CEB n. ${ }^{0} 11 / 2012$, que deu origem à Resolução CNE/CEB n. ${ }^{0}$ 06/2012, que estabelece que Educação Profissional

É uma importante estratégia para o efetivo acesso às conquistas científicas e tecnológicas da sociedade. Impõe a superação do enfoque tradicional da formação profissional baseado apenas na preparação para execução de um determinado conjunto de tarefas. Requer, além do domínio operacional de um determinado fazer, a compreensão global do processo produtivo, com a apreensão do saber tecnológico, a valorização da cultura do trabalho e a mobilização dos valores necessários à tomada de decisões no mundo do trabalho. Deve estar centrada no compromisso de oferta de uma Educação ampla e politécnica (FDE/CONIF, 2016, p. 9).

\footnotetext{
${ }^{8}$ A Plataforma Nilo Peçanha (PNL) consiste em uma importante fonte de acesso à pesquisa, disponibilizando à sociedade, em ambiente virtual, informações acerca de coleta, validação e disseminação das estatísticas oficiais da Rede Federal de Educação Profissional, Cientifica e Tecnológica.
} 
DOI: 10.12957/e-mosaicos.2019.46491

Essa proposição reitera que a educação ofertada pela Rede Federal visa ao acesso ao conhecimento científico e tecnológico acumulado pela sociedade, afastando-se de uma educação destinada apenas para formação de mão de obra, amparando, para isso, na concepção de formação omnilateral.

A minuta aborda uma análise acerca de como as alterações na LDB podem influenciar a oferta dos Cursos Integrados da Rede Federal, primeiramente ressaltando que a oferta dos Cursos Integrados é uma determinação legal respaldada na Resolução CNE/CEB n. ${ }^{\circ}$ 06/2012. Desse modo, é evidenciado que a oferta dos Cursos Integrados não se confronta com a Lei n. ${ }^{\circ}$ 13.415/2017, que alterou a LDB, conforme exposto

É importante ressaltar, por fim, que a Lei n. ${ }^{\circ} 13.415 / 2017$ alterou a LDB no que diz respeito ao Ensino Médio, como última etapa da Educação Básica, e não no capítulo que diz respeito à Educação Profissional. A continuidade da oferta dos Cursos Integrados na Rede Federal de EPCT continua sendo uma determinação legal, na lei educacional vigente e não está em contradição, do ponto de vista legal, com as alterações na LDB (FDE/CONIF, 2016, p. 13).

Sobre a qualidade da educação profissional dos cursos técnicos integrados, foi posto no documento que essa não se pode se limitar a rendimentos de exames padronizados. De acordo com Freitas (2018), ao se colocar os testes padronizados como foco da escola, transformando suas ações com base nessas referências de qualidade, ocorre, dessa maneira, a ocultação do debate sobre as reais finalidades educativas, favorecendo a captura da ação pedagógica pelo status quo. Desse modo, de acordo com a minuta,

o conceito de qualidade educacional do Ensino Médio Integrado da Rede Federal não deve se pautar apenas no uso dos resultados de exames direcionados aos estudantes (ENEM e outros exames), porque essa perspectiva não consegue responder à complexidade de todo processo educativo no contexto do Ensino Médio Integrado ofertado pela Rede Federal. Por outro lado, preparar estudantes para exames não é o objetivo e nem resume o trabalho desenvolvido pelos IFs (FDE/CONIF, 2016, p. 14).

Portanto, após a análise da minuta dos Parâmetros Gerais do Currículo Integrado de EPCT, é possível depreender que se trata de um importante documento que vislumbra princípios e objetivos da Rede Federal no que tange à discussão sobre a organização curricular e as práticas educativas. Em síntese, o conteúdo do documento apresenta elementos teóricos e legais que justificam a defesa de um 
DOI: $10.12957 /$ e-mosaicos.2019.46491

modelo educacional centrado na ideia de trabalho e a pesquisa como princípio educativo que perpassa também o entendimento da curricularização da extensão ${ }^{9}$ como possibilidade de concretização da indissociabilidade ensino, pesquisa e extensão também na educação básica. Logo, mostra-se resistente à lógica posta pelos neoliberais no campo educacional.

A esse respeito, importa salientar que o currículo integrado constitui-se um desafio que perpassa as discussões no campo educacional, instigando os profissionais da educação a buscar formas de efetivá-lo que implicam práticas como interdisciplinaridade, transversalidade, contextualização, temas geradores etc. Isso com a finalidade de garantir maior integração dos saberes escolares com os saberes cotidianos dos estudantes, de modo a combater a visão hierárquica e dogmática do conhecimento. Ora, a compreensão de formação integrada exige a superação de concepções e práticas fragmentadoras do conhecimento humano, que desconsidera sua totalidade humana. O desafio é, pois, identificar as formas de integração, ou seja, o modo de fazer a mediação entre diferentes saberes, o que não implica ignorar o currículo disciplinar.

\section{REFORMA DO ENSINO MÉdIO - LEI 13.415/2017: DESAFIOS À EDUCAÇÃo PROFISSIONAL EM TEMPOS DE NEOLIBERALISMO}

No contexto do pós-golpe jurídico-parlamentar de 2016, foi promulgada a Lei no 13.415/2017, responsável pela "nova" reforma do Ensino Médio em vigor, que objetiva a flexibilização da matriz curricular, o que possibilita ao estudante optar por certa área de conhecimento para aprimorar seus estudos. A atual matriz prevê uma parte comum e obrigatória a todas as escolas por meio da Base Nacional Comum Curricular (BNCC) e outra seção flexível. Tal mudança é justificada pelo objetivo de aproximar ainda mais a escola das novas demandas profissionais do mercado de trabalho. Nesse caso, a BNCC define as competências e conhecimentos oferecidos a todos os estudantes na parte comum em 1.800 horas, envolvendo linguagens e suas tecnologias; matemática e suas tecnologias; ciências da natureza e suas tecnologias; ciências humanas e sociais aplicadas e a formação técnica e profissional. Opera, pois, um modelo pedagógico que busca contemplar a ideia de que uma integração com a educação profissional, sob a prerrogativa de que a formação, ao mesmo tempo, do jovem para o mundo do trabalho e a prática social e a continuidade de estudos, articula metas de interesse nacional com os interesses do público específico.

\footnotetext{
${ }^{9}$ A Resolução n. ${ }^{0}$ 7, de 18 de dezembro de 2018, institui as Diretrizes para a Extensão na Educação Superior entre outras providências. Estabelece, em seu art. 30, que a extensão na educação superior brasileira consiste numa atividade que deve estar integrada à matriz curricular e à pesquisa, ocorrendo, assim, de modo interdisciplinar, político, educacional, cultural, científico, tecnológico, na procura de viabilizar a interação entre as instituições de ensino superior e os outros âmbitos da sociedade por meio da produção e da aplicação dos saberes, em conexão permanente com o ensino e a pesquisa (BRASIL, 2018).
} 
DOI: $10.12957 /$ e-mosaicos.2019.46491

Nesse sentido, destaca-se que a preocupação com a formação da classe trabalhadora em fase escolar e com aspectos como a evasão e a defasagem de aprendizagem não é nova e tem gerado distintas abordagens na busca da investigação de suas origens e no desenvolvimento de projetos necessários para a sua suplantação. Destarte, considera-se que a constituição de um projeto de educação realça as disputas de concepções e estratégias de cada período histórico. Segundo Motta e Frigotto (2017), a ideia de promover no Ensino Médio o desenvolvimento de habilidades e competências que maximizam a inserção do jovem no mercado de trabalho constitui-se uma ideologia, injusta e ardilosa, pois os "cortes no orçamento da educação e os repasses de recursos públicos para setores privados ofertarem cursos aligeirados e de baixo valor tecnológico agregado vão de encontro à ideologia do capital humano" (Ibid., p. 361). Isso implica pensar que a trajetória de implementação e uma política pautada pela imbricada relação entre a formação para o trabalho e o ensino médio não deveriam acontecer de modo impositivo, via Medida Provisória ou decretos, visto que pressupõe efetiva discussão e o enfretamento com diferentes frações da sociedade, inclusive com os contrários.

Portanto, apenas propor a formação da classe trabalhadora em consonância com o discurso produtivista e suas demandas atuais, como a flexibilidade e adaptabilidade, não é suficiente para garantir a melhoria da qualidade da educação. Para o autor, a melhoria da qualidade da educação brasileira incide no aumento e não no congelamento dos investimentos nas instituições públicas, conforme posto na Emenda Constitucional n. ${ }^{0}$ 95/2016, que prevê drástica limitação para os gastos públicos do governo federal por vinte anos.

Nesse contexto, anula-se o horizonte da formação omnilateral e mais uma vez entra em cena a ideia de educação como mercadoria, na qual existe a ligação dos objetivos das políticas educacionais às demandas econômicas e de livre mercado. Para Freitas (2018, p. 10), a contemporaneidade da educação brasileira conta com a forte retomada dos ideais neoliberais "a partir do Golpe jurídico-parlamentar de 2016 que afastou a coalizão do PT do poder, colocando em cena a retomada do liberalismo econômico". Para o autor, tal realidade influencia a educação brasileira na medida em que prevê a inclusão da escola no livre mercado por meio de um movimento global de reforma da educação.

Dentre os desdobramentos desse cenário, o "novo" Ensino Médio brasileiro, empreendido pelo atual governo de Michel Temer (2016-2017), é inquirido por Frigotto e outros pesquisadores brasileiros, que engendram questionamentos quanto à origem das reformas educacionais que o ensino propedêutico e profissionalizante têm experimentado desde a Reforma Capanema, promulgada em 9 de abril de 1942, Lei Orgânica do Ensino Secundário, elitista e conservadora, que materializou o dualismo educacional ao definir que o ensino secundário público seria proposto às elites dominantes, e o ensino profissionalizante para as classes populares. Realidade análoga ao atual contexto do Ensino Médio brasileiro calcado no imperativo de produtivista. 
DOI: 10.12957/e-mosaicos.2019.46491

Na concepção de Frigotto (2017), a Lei n.o 13.415/2017 não promove a necessária ruptura com o modelo dualista educacional brasileiro (uma escola para pobres e uma escola para os ricos), por condensar tríplice retrocesso histórico: criação de itinerários estanques não equivalentes; profissionalização precária frente ao orçamento insuficiente e divisão classista à luz do argumento de "livre escolha" pelo ensino profissionalizante nas esferas pública e privada. Em suas palavras, a Reforma

apresenta rigidez no tocante à implementação das disciplinas recomendadas pelos organismos internacionais, intelectuais coletivos e orgânicos do capital e do mercado e na negação tácita do conhecimento básico para uma leitura autônoma da realidade social, esta acobertada pela delegação da "livre escolha" do jovem dentre as opções ofertadas. [...] trata-se de uma contrarreforma que expressa e consolida o projeto da classe dominante brasileira em sua marca antinacional, antipovo, antieducação pública, que nega os fundamentos das ciências que permitem aos jovens entender e dominar como funciona o mundo das coisas e a sociedade humana (FRIGOTTO, 2017, p. 368-369).

Nesse sentido, o alerta de Frigotto (2017) sobre os malefícios de um projeto educacional que não prima pela equidade social, por desconsiderar os problemas estruturais do ensino médio brasileiro, seja a desvalorização dos professores, seja o número de alunos por classe, seja a defasagem da escola perante as novas tecnologias do mundo digital, denuncia que essa problemática é contínua no curso da história da educação brasileira. A esse respeito, é oportuno frisar que o Ensino Médio contemporâneo retoma elementos estruturantes da Lei de Diretrizes e Bases n. ${ }^{\circ} 5692 / 71$, segundo a qual o ensino médio assume um caráter essencialmente profissionalizante devido à crença de que tal grau de ensino deveria, sobretudo, treinar os estudantes para o mundo do trabalho. No entanto, vale lembrar que essa proposição foi calamitosa e operou, na verdade, para "conter o aumento da demanda de vagas aos cursos superiores" (NASCIMENTO, 2007, p. 83) e, com isso, também fragmentar ainda mais a juventude, entre aqueles que ascenderiam ou não ao Ensino Superior. Trata-se, pois, do risco de condenar significativa parte da juventude à condição de pura mão de obra para o mercado.

Para Motta e Frigotto (2017), promover no ensino médio o desenvolvimento de habilidades e competências, que priorizam a inserção do jovem no mercado de trabalho, se estabelece em uma ideologia, injusta e ardilosa, uma vez que os "cortes no orçamento da educação e os repasses de recursos públicos para setores privados ofertarem cursos aligeirados e de baixo valor tecnológico agregado vão de encontro à ideologia do capital humano (Ibid., p. 361)". Na visão dos autores, pensar a formação de jovens em concordância com a lógica produtivista e suas exigências 
DOI: $10.12957 / \mathrm{e}-\mathrm{mosaicos} .2019 .46491$

contemporâneas, como a flexibilidade e adaptabilidade, não é suficiente para se garantir a melhoria da qualidade da educação.

Frigotto e Ciavatta (2005) afirmam que se criam, continuamente, novos termos, novas palavras, seja para expressar novas realidades engendradas pela vida social, seja para projetar, ideologicamente, novas ideias que queremos que se tornem realidade pela aceitação social que possam vir a ter. Nesse sentido, alertam sobre os malefícios de um projeto educacional que não prima pela equidade social por desconsiderar os problemas estruturais do ensino médio brasileiro. $\mathrm{O}$ arranjo de tal cenário possibilita conjeturar que a reforma instituída, em termos conceituais, revela não primar pela real superação das complexidades existentes no ensino médio, mas sim reforçar fortemente o processo de desenvolvimento do capitalismo no Brasil, sem considerar, portanto, expressões coletivas e democráticas, princípios e métodos pedagógicos humanistas voltados para a integração.

Nesse contexto, anula-se o horizonte da formação omnilateral, e mais uma vez entra em cena a ideia de educação como mercadoria, na qual existe a ligação dos objetivos das políticas educacionais às demandas econômicas e de livre mercado. Para Freitas (2018, p. 10), a contemporaneidade da educação brasileira conta com a forte retomada dos ideais neoliberais "a partir do Golpe jurídicoparlamentar de 2016 que afastou a coalizão do PT do poder, colocando em cena a retomada do liberalismo econômico". Para o autor, tal realidade influencia a educação brasileira na medida em que prevê a inclusão da escola no livre mercado por meio de um movimento global de reforma da educação.

Segundo Freitas (2018), a sociedade neoliberal pressupõe que a qualidade da educação depende da inserção das escolas, professores e estudantes em um jogo concorrencial, do qual ela insurgiria, então, sem a intervenção do Estado. Nesse caso, as tentativas de terceirização e de privatização, a dinâmica de padronização por meio de base nacional comum curricular e a implementação de sistemas de avaliação centrados em testes censitários e na responsabilização meritocrática são tomados como indutores da inclusão da educação no mercado. De acordo com o autor, tais medidas de caráter neoliberal atrapalham o desenvolvimento de outras alternativas mais qualitativas e éticas e de se transformar a realidade precária da escola pública brasileira, corroborando a inércia dos processos de real qualificação da educação.

Desse modo, o discurso neoliberal busca enraizar, no senso comum, que o Estado não é bom dirigente, sendo esse o motivo responsável pela crise de eficiência, eficácia e produtividade educacional. Sobre isso, Gentili (1996, p. 17) afirma que "os sistemas educacionais contemporâneos não enfrentam, sob a perspectiva neoliberal, uma crise de democratização, mas uma crise gerencial". Através desse discurso é possível perceber a intenção de transformar a escola em uma "empresa". E esse processo é denominado por Freitas (2018) como as 
DOI: $10.12957 /$ e-mosaicos.2019.46491

"reformas empresariais da educação ${ }^{10 "}$.

Com efeito, o sistema público vai sendo destruído gradativamente de acordo com a diminuição de verba recebida, pois essa verba passa a ser destinada ao financiamento do setor privado. Mediante essa lógica, elimina-se a gestão pública do Estado sobre a Educação, possibilitando, assim, o alcance do objetivo neoliberal de se "obter pelo acesso à gestão, controle do processo educativo da juventude [...] (FREITAS, 2018, p. 55)". Sobre essa intenção de controle,

a insistência da reforma empresarial para que a escola se restrinja à "aprendizagem das disciplinas básicas" é uma demanda de longa data do status quo, assustado com a possibilidade de que os processos de trabalho inevitavelmente baseados em maior uso de tecnologia, ao demandarem mais instrução, acabem por "educar demais a mão de obra", levando-a a níveis de conscientização maiores que mobilizem e coloquem em xeque o próprio status quo (FREITAS, 2018, p. 83). ${ }^{11}$

Destarte, o interesse neoliberal sobre a educação consiste na efetivação de uma educação hegemônica através do controle dos processos educativos, buscando impedir que os filhos dos trabalhadores possam ter a mesma educação que a camada dirigente, o que ameaçaria a organização atual, baseada na divisão social do trabalho inerente status $q u o^{12}$. Ou seja, os neoliberais lutam para construir uma escola que sirva aos seus interesses. Nessa perspectiva, está implícita a separação entre aqueles que concebem e controlam o processo de trabalho e aqueles que irão dar-Ihe cumprimento.

Essa concepção motiva a defesa da profissionalização no ensino médio, amplamente difundida, e atualmente implementada pela Reforma do Ensino Médio (Lei n. ${ }^{\circ}$ 13.415, sancionada em 16 de fevereiro de 2017), priorizando assim o dualismo histórico existente, em que a educação profissional é destinada àqueles que estão sendo preparados para executar o processo de trabalho, e a educação científico-acadêmica ofertada àqueles que vão conceber e controlar esse processo. Essa visão que separa a educação geral, propedêutica, da educação específica e profissionalizante, é capaz de reduzir a educação profissional a treinamentos para

\footnotetext{
10 Reforma empresarial da educação trata-se de um movimento baseado na articulação entre liberalismo econômico com autoritarismo social, denominado "nova direita", que visa à transformação da escola em "empresa", inserindo-a no livre mercado e desvinculando-a da interferência do Estado por meio de uma série de recomendações, como a privatização, a padronização através de bases comuns curriculares, a avaliação baseada em testes censitários e a responsabilização meritocrática (FREITAS, 2018).

11 Grifos do autor.

${ }^{12} \mathrm{~A}$ expressão latina status quo significa "a intenção de se manter o atual, seja cenário, situação ou condição etc.
} 
DOI: $10.12957 /$ e-mosaicos.2019.46491

preenchimentos de postos de trabalho.

\section{CONSIDERAÇÕES FINAIS}

Conforme Nosella (1995), "escola do dizer" e "escola do fazer" são divisões estruturais do sistema educativo no modo capitalista de produção, ou seja, prevalecem uma escola de formação das elites e outra escola de formação do proletariado. Nessa perspectiva, está implícita a separação entre aqueles que concebem e controlam o processo de trabalho e aqueles que irão dar cumprimento; a educação profissional destinada àqueles que estão sendo preparados para executar o processo de trabalho e a educação científico-acadêmica ofertada àqueles que vão conceber e controlar esse processo. Essa visão que separa a educação geral, propedêutica, da educação específica e profissionalizante é capaz de reduzir a educação profissional a treinamentos para preenchimento de postos de trabalho.

Sob esse prisma, objetivando o enfrentamento dos desafios postos por essa realidade, considera-se essencial que a escola se constitua como um espaço privilegiado de troca de saberes, onde os trabalhadores sejam vistos como sujeitos pensantes e ativos e não apenas potenciais empregados. Concordamos com Mészáros quanto ao verdadeiro sentido da educação, que não é o negócio, e sim criação. Portanto, a educação vigente nas escolas deveria formar para a vida e não para o mercado de trabalho, e seu papel como propulsor de conhecimento incide em afastar o sujeito do individualismo produzido pelo capital, que delineia as relações de competição orientadas atualmente pelo sistema capitalista. Trata-se da tentativa de se ultrapassar a lógica desumanizadora do capital, que tem como bases de sustentação o individualismo, o lucro e a competição, para arquitetar a sociedade tendo como ponto nuclear o ser humano.

Cabe, pois, buscar e "reivindicar uma educação plena para toda a vida, para que seja possível colocar em perspectiva a sua parte formal, a fim de instituir, também aí, uma reforma radical" (MÉSZÁROS, 2005, p. 55). Ora, o objetivo primordial da educação é o de elaborar, desenvolver e realizar as transformações políticas, econômicas, culturais e sociais necessárias. Uma educação empenhada na construção de um outro mundo possível, que prime pelo ser humano e não apenas pela sua atividade de trabalho.

Com efeito, a educação integrada fundamenta-se em princípios científicos e tecnológicos que se instituem num espaço de síntese entre a prática e a teoria, entre o trabalho manual e o intelectual. Busca-se um projeto que vá além da educação profissional baseada no conhecimento e na aquisição de técnicas e das particularidades do mundo do trabalho, a reflexão sobre as vivências, as experiências e o saber histórico e social do sujeito. Concebe-se, assim, uma educação humanista, na qual o humano não deve existir somente para o mundo produtivo do trabalho. 
DOI: $10.12957 /$ e-mosaicos.2019.46491

\section{REFERÊNCIAS}

BRASIL. Decreto-Lei no 9.613, de 20 de agosto de 1946. Disponível em: $<$ https://www2.camara.leg.br/legin/fed/declei/1940-1949/decreto-lei-9613-20agosto-1946-453681-publicacaooriginal-1-pe.html>. Acesso em: 20 fev. 2019.

BRASIL. Decreto no 547, de 18 de abril de 1969. Disponível em: $<$ https://www2.camara.leg.br/le gin/fed/declei/1960-1969/decreto-lei-547-18-abril1969-374120-publicacaooriginal-1-p e. htm >. Acesso em: 12 fev. 2019.

BRASIL. Decreto no 2.208, de 17 de abril de 1997. Disponível em: <http://www.planalto.gov.br/ccivil_03/decreto/D2208.htm>. Acesso em: $14 \mathrm{fev}$. 2019.

BRASIL. Decreto no 5.154, de 23 de julho de 2004. Disponível em: <http://www.plan alto.gov.br/ccivil_03/_ato2004 2006/2004/decreto/d5154.htm>. Acesso em: 22 fev. 2019.

BRASIL. Decreto $n^{\circ}$ 7.566, de 1909. Disponível em: <https://www2.camara. leg.br/ legin/fed/ decret/ 1900-1909/decreto-7566-23-setembro-1909-525411-normape.html>. Acesso em: 25 jan. 2019.

BRASIL. Decreto $n^{\circ} 18.890$, de 18 de abril de 1931. Disponível em: $<$ https://www2.camara.leg.br/ legin/fed/decret/1930-1939/decreto-19890-18-abril193 1-504631-publicacaooriginal-141245-pe.html>. Acesso em: 4 jan. 2019.

BRASIL. Decreto no 21.214, de 4 de abril de 1932. Disponível em: <https://www2.camara.leg.br/legin/fed/decret/1930-1939/decreto-21241-4-abril1932-503517-norma-pe.html>. Acesso em: 25 fev. 2019.

BRASIL. Decreto no 4.127, de 25 de fevereiro de 1942. Disponível em: <https://www 2.camara.leg.br/legin/fed/declei/1940-1949/decreto-lei-4127-25-fevereiro-1942414123 -publicacaooriginal-1-pe.html>. Acesso em: 20 fev. 2019. 
DOI: $10.12957 / \mathrm{e}-\mathrm{mosaicos} .2019 .46491$

BRASIL. Decreto-Lei no 4.073, de 30 de janeiro de 1942. Disponível em: <https:// www2.camara.leg.br/legin/fed/declei/1940-1949/decreto-lei-4073-30-janeiro-1942414503-publicacaooriginal-1-pe.html>. Acesso em: 22 fev. 2019.

BRASIL. Decreto-Lei no 4.244, de 9 de abril de 1942. Disponível em: <https://www2 .camara.leg.br/legin/fed/declei/1940-1949/decreto-lei-4244-9-abril1942-414155-133712-pe.html>. Acesso em: 25 fev. 2019.

BRASIL. Decreto-Lei no 6.141, de 28 de dezembro de 1943. Disponível em: <https://www2.camara.leg.br/legin/fed/declei/1940-1949/decreto-lei-6141-28dezembro -1943-416183-publicacaooriginal-1-pe.html>. Acesso em: 20 fev. 2019.

BRASIL. Lei no 5.692, de 11 de agosto de 1971. Disponível em: $<$ https://presrepublica.jusbrasil.com.br/legislacao/128525/lei-de-diretrizes-e-basede-1971-lei-5692-71>. Acesso em: 9 fev. 2019.

BRASIL. Lei no 11.892, de 29 de dezembro de 2008. Disponível em: <http://www.planalto.gov.br/ccivil_03/_ato2007-2010/2008/lei/l11892.htm>. Acesso em: 15 jan. 2019.

BRASIL. Lei no 6.545, de 30 de junho de 1978. Disponível em: <http://www.planalto.gov.br/ccivil_03/LEIS/L6545.htm>. Acesso em: 10 fev. 2019.

BRASIL. Lei no 13.415, de 16 de fevereiro de 2017. Disponível em: <http://www.planalto.gov.br/ccivil_03/_ato2015-2018/2017/lei/l13415.htm>. Acesso em: 22 fev. 2019.

BRASIL. Lei no 4.024, de 20 de dezembro de 1961. Disponível em: <https://www2.camara.leg.br/legin/fed/lei/1960-1969/lei-4024-20-dezembro-1961353722-publicacaooriginal-1-pl.html >. Acesso em: 10 mar. 2019.

BRASIL. Lei no 8.948, de 8 de dezembro de 1994. Disponível em: <http://www.planalto.gov.br/ccivil_03/leis/l8948.htm>. Acesso em: 12 fev. 2019.

BRASIL. Lei no 9.394, de 20 de dezembro de 1996. Disponível em: <http://www.planalto.gov.br/ccivil_03/leis/l9394.htm>. Acesso em: 11 mar. 2019.

BRASIL. Centenário da Rede Federal de Educação Profissional e Tecnológica. Brasília: MEC, 2009.

CUNHA, L. A. O ensino profissional na irradiação do industrialismo. São Paulo: Editora Unesp; Brasília, DF: FLACSO, 2005. 
DOI: $10.12957 / \mathrm{e}-\mathrm{mosaicos} .2019 .46491$

DOURADO, Luiz. Reforma do Estado e as políticas para a educação superior no Brasil nos anos 90. Educação \& Sociedade. Campinas, v. 23, n. 80, p. 234-252, set. 2002.

FDE/CONIF. Documento Base para a promoção da formação integral, fortalecimento do ensino médio integrado e implementação do currículo integrado no âmbito das Instituições da Rede EPCT conforme Lei 11.892/2008. Brasília, 11 maio 2016.

Disponível em: http://portal1.iff.edu.br/nossos-campi/campos- centro/diretoria-deeducacao-basica-e-profissional/arquivos-da-diretoria-de-ensino-basico-e profissional/documento-base-ensino-medio-integrado-na-rede-epct-fde-maio2016.pdf>. Acesso em: 5 fev. 2019.

FREITAS, L. C. A reforma empresarial da educação: nova direita, velhas ideias. São Paulo: Expressão Popular, 2018.

FRIGOTTO, Gaudêncio. A gênese das teses do Escola sem Partido: esfinge e ovo de serpente que ameaçam a sociedade e a educação. In: FRIGOTTO, Gaudêncio (Org.). Escola "sem" Partido: esfinge que ameaça a educação e a sociedade brasileira. Rio de Janeiro: UERJ, LPP, 2017. p. 361-369.

GENTILI, Pablo. Neoliberalismo e educação: manual do usuário. In: SILVA, Tomaz Tadeu da; GENTILI, Pablo (Org.). Escola S.A.: quem ganha e quem perde no mercado educacional do neoliberalismo. Brasília, DF: CNTE, 1996. p. 9-49.

KUENZER, Acácia Z. A educação profissional nos anos 2000: a dimensão subordinada das políticas de inclusão. Educação \& Sociedade. Campinas, v. 27, n. 96, p. 877-910, 2006. Disponível em: <http://dx.doi.org/10.1590/S0101-73302006000300012>. Acesso em: 3 fev. 2019.

KUENZER, Acácia Z. Ensino médio e profissional: as políticas do Estado neoliberal. São Paulo: Cortez, 1997.

MÉSZÁROS, István. A educação para além do capital. 2. ed. São Paulo: Boitempo, 2008.

MOTTA, Vânia Cardoso; FRIGOTTO, Gaudêncio. Por que a urgência da Reforma do Ensino Médio? Medida Provisória n. ${ }^{\circ}$ 746/2016 (Lei n. ${ }^{0}$ 13.415/2017). Educação \& Sociedade. Campinas, 2017, v. 38, n.139, p. 355-372, 2017.

MOURA, Dante Henrique. Educação básica e educação profissional e tecnológica: dualidade histórica e perspectiva de integração. Holos. Natal, v. 2, 2007.

NASCIMENTO, Manoel Nelito M. Ensino Médio no Brasil: determinações históricas. 
DOI: $10.12957 / \mathrm{e}-\mathrm{mosaicos} .2019 .46491$

Publicatio UEPG: Ciências Humanas, Ciências Sociais

Aplicadas, Linguística, Letras e Artes, Ponta Grossa, v. 15, n.1, jun. 2007.

Disponívelem:<www.revistas2.uepg.br/index.php/sociais/article/download/2812/209

7>. Acesso em: 22 jan. 2017.

NOSELLA, P. Prefácio. In: MANACORDA, M. (Org.). História da Educação: da antiguidade aos nossos dias. 4. ed. São Paulo: Cortez, 1995.

RAMOS, Marise. Concepção de ensino médio integrado. Forum EJA. Mossoró-RN: UFRN, 2007. Disponível em: http://forumeja.org.br/gosites/forumeja.org.br.go/files/ concepção_do_ensino_medio_integrado5.pdf>. Acesso em: 12 jan. 2019.

SAVIANI, Demerval. História das ideias pedagógicas no Brasil. Campinas: Autores Associados, 2007.

Recebido em 05 de novembro de 2019

Aceito em 09 de dezembro de 2019

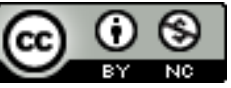

A e-Mosaicos Revista Multidisciplinar de Ensino, Pesquisa, Extensão e Cultura do Instituto de Aplicação Fernando Rodrigues da Silveira (CAp-UERJ) está licenciada com uma Licença Creative Commons - Atribuição-NãoComercial 4.0 Internacional.

Os direitos autorais de todos os trabalhos publicados na revista pertencem ao(s) seu(s) autor(es) e coautor(es), com o direito de primeira publicação cedido à e-Mosaicos.

Os artigos publicados são de acesso público, de uso gratuito, com atribuição de autoria obrigatória, para aplicações de finalidade educacional e não-comercial, de acordo com o modelo de licenciamento Creative Commons adotado pela revista. 